\title{
Transcriptome analysis of Phytophthora infestans and Colletotrichum coccodes in tomato to reveal resistance mechanisms
}

\author{
Abbas Saidi*, Zahra Hajibarat, Zohreh Hajibarat \\ Department of Plant Sciences and Biotechnology, Faculty of Life Sciences and Biotechnology, Shabid Beheshti University, G. C., Tebran, Iran
}

Received 1st July 2019 / Accepted 15th January 2020

\begin{abstract}
Tomato is considered as an important commercial crop and protective food and it's yield is extremely affected by different pathogens. Such harmful pathogens severely affecting tomato include Phytophthora infestans (oomycete) and Colletotrichum coccodes (fungi). In this study, gene expression analysis was performed using the microarray datasets available in the public database to investigate differentially expressed genes DEGs under developmental and anatomy conditions and consequently constructing the predicted PPI (Protein-protein interaction) network. Here, a comparison of abundances revealed that 51 genes were differentially expressed due to oomycete and fungi stresses in tomato. Expression analysis revealed that Soly06g007510.3 was up-regulated whereas Solyc05g008850.3 was down-regulated in all developmental stages and anatomy conditions to manage auxin metabolism under fungi and oomycete infections in tomato. The gene ontology included cellular metabolic and organic substance metabolic processes, cellular biosynthetic, organic substance biosynthetic, and cellular macromolecule metabolic process, chloroplast, intracellular membrane-bounded organelle, heterocyclic compound binding, organic cyclic compound binding, ion binding, binding, and catalytic activity. Analysis of cis-elements illustrated that 12 most general cis-regulatory elements (CATT-box, TATA-box, MYB, MYC, ABRE, G-box, Box 4, AAGAA-motif, MBS, as-1, TGACG-motif, and CGTCA-motif) were identified in promoter region. The highest frequency of cis-elements included CAT'T-box and TATA-box in response to the pathogens at different growth stages in tomato. Our findings can provide a better insight to the regulatory mechanisms involved in response to fungi and oomycete infection in tomato which can aid to improve the efficiency of developing tomato varieties.
\end{abstract}

Keywords: Microarray, co-expressed, gene ontology, oomycete, fungi

\section{INTRODUCTION}

Tomato, Solanum bycopersicum, formerly, Lycopersicon esculentum Mill., is one of the most important vegetable crops in the world and a good source of organic nutrients. Tomato is considered as a major constituent in many foods due to its essential nutrients like lycopene, beta-carotene, and flavonoids (Raiola et al., 2014). Its genome has been sequenced and is an excellent model for basic research. Plant diseases cause substantial losses in crop yield throughout the world.
Pathogens can promote infection at different phases such as fruit ripening complete, ripening, and fruit formation, spreading quickly after spores attack the tissues (Prusky et al., 2009). Since plants are constantly exposed to many microbial infections such as fungi and oomycetes, they have developed several defense mechanisms to withstand the microbial attacks such as hardening of cell wall and programmed cell death (Tyler and Rouxel, 2012; Wirthmueller et al., 2013).

*Author for correspondence: Abbas Saidi, Department of Plant Sciences and Biotechnology, Faculty of Life Sciences and Biotechnology, Shahid Beheshti University, G. C., Tehran, Iran. Email - abbas.saidi@gmail.com 
Resistant/tolerant plants possess various immune receptors to detect pathogen-derived molecules containing mediators produced by the pathogens to initiate infection (Stam et al., 2014). There are two procedures for detection of pathogen mediators namely pathogen-associated molecular patterns (PAMPS) and effector-triggered immunity (ETI) which are localized on the plasma membrane and intracellular.

Phytophthora infestans and Colletotrichum coccodes can infect both non-ripened and ripened fruits. Phytophthora infestans (oomycete) and Colletotrichum coccodes (fungi) are the causal agents of late blight and anthracnose on tomato, respectively. From morphology and habitat point of view, fungi and oomycetes have been considered to be similar and traditionally categorized in one class. These pathogens have basic differences from each other such as cell wall composition. For example, cell walls of oomycetes are formed of cellulose rather than chitin as in fungi. Also, fungi have haploid nuclei whereas oomycetes contain diploid nuclei. In addition, oomycetes utilize diaminopimelate (or DAP) pathways for lysine synthesis (Barr, 1983), whereas fungi use $\alpha$-aminoadipate (or AAA) pathway. Oomycetes and fungi are different in their promoter regions. Oomycetes have an initiator element (19-nt) as its core sequence instead of TATA box in promoter regions in fungi (McLeod et al., 2004). Both pathogens can infect leaves and fruits, cause massive deaths of plants, and result in reduced yield in tomato (Nowicki et al., 2012; Gudero et al., 2018).

Breeding technologies are crucial for improving crop production especially tomato with an exponentially growing population in the face of biotic and abiotic stresses (Tester and Langridge, 2010). The most classic breeding approach to improve tomato has been hybridization followed by selection. An important challenge in classic breeding is linkage drag which the genes of interest may be tightly linked to the unfavorable genes (Fentik, 2017). Classic plant breeding is based on phenotypic selection of elite individuals consequently there are considerable difficulties due to genotype-environment interactions. Besides, testing procedures in classic breeding may be many times more difficult, unreliable, and expensive. There are new approaches for evaluation of plants under stress conditions such as genomics, marker-assisted selection (MAS), and transcriptomics. MAS is an indirect selection process in genomic regions that are implicated in the expression of traits of interest through molecular markers. However, MAS possesses several limitations such as costly, availability of suitable markers, and staff resources for sample and data handling (Brumlop and Finckh, 2011). It is evident that SSR markers are one of the most important markers utilized in molecular mapping and MAS selection. Microsatellites are multi-allelic and are considered to be one of the best markers for detection of polymorphism. However, development of SSR markers is expensive, laborious, time-consuming (Stępień et al., 2007), and in low frequency in plants (Senan et al., 2014). With the advantages of highly parallel and flexibility, microarray has become increasingly important in crop genetic studies, and it is well suited for applications such as QTL analysis and genotyping (Miller and Tang, 2009). Cutting edge technologies such as microarray is a new powerful tool for studying the molecular basis of interaction on a scale that is impossible using conventional analysis (Lenka et al., 2009). This technique makes it possible to determine the expression of thousands of genes simultaneously.

In the current research, microarray data was used to survey and compare gene expression patterns in tomato pericarp and leaves under two pathogen factors, Phytophthora infestans and Colletotrichum coccodes. Analysis of differentially expressed genes has created a new perspective on important processes in protecting the pericarp and leaf growth against oomycete and fungi presence in tomato as well as introducing genes to transfer disease resistance into plants. Expression analysis was performed to identify the candidate genes having higher potential value in tomato breeding.

\section{MATERIALS AND METHODS}

The microarray data (CEL file) was taken from the GEO/NCBI under the sample numbers GSE33177 and GSE21999. In this study, microarray data was collected from 15 samples and the treatments included tomato leaves from 
non-inoculated plants, tomato leaves from inoculated plants with Phytophthora infestans, tomato fruit wound inoculation by Colletotrichum coccodes, tomato fruit wound control, tomato fruit ammonium treatment, and tomato fruit PBS control in two tomato cultivars from NCBI (http://www.ncbi.nlm.nih.gov/gds) (Table 1). Analysis of data was performed by fold change which was based on $\log _{2}$ ratio, followed by normalizing the data. Then the ratio expression of the genes examined under oomycetes and fungi infections were compared to control and the DEGs were selected by $\mathrm{p}$-value $<0.05$ as the statistical significance. The filtered data with DEGs $>1$ was considered as up-regulated genes and DEGs $<-1$ was considered as down regulated. The DAVID Gene ID Conversion Tool (DICT) is able to convert Affymetrix IDs to gene names and to detect the function of genes affected by fungi and oomycete (https://david.ncifcrf.gov). In this study, analysis of data was performed by fold change which was based on $\log _{2}$ ratio, followed by normalizing the data (the ratio expression of the genes examined under fungi and oomycete infection to control). String (http://string-db.org/) was used to identify coexpressed genes and to draw the protein-protein interaction networks (Szklarczyk et al., 2016).

\section{In silico analysis of genes expression}

Genevestigator is a web-based system which provides meta-analysis of transcriptomes. Metaanalysis of transcriptomes is based on large-scale and systematic combination of normalized and quality-controlled expression data with experimental context variables using ontologies (e.g. anatomy, development, perturbation). To identify the differential gene expression under pathogen (fungi and oomycete) infections, microarray expression data was explored (https://genevestigator.com/gv/; Zimmermann et al. 2008) from Solanum lycopersicum database using Affymatrix Tomato Genome Array. In addition, 'Perturbations' tool was utilized to find out the differential gene expression under fungi and oomycete infections (https://genevestigator. $\mathrm{com} / \mathrm{gv} / \mathrm{start} / \mathrm{start}$.jsp) during developmental stages. The fold change in gene expression was detected using filter 1 fold as benchmark. Compendium-wide analysis in genevestigator program showing the fold changes in the expression of DEGs under different tissue and stage-specific tissue conditions were used to generate the gene expression heatmap. Red/white color scheme where "Red" color represents upregulation and "white" color represents downregulation of respective genes were used to designate the heatmap.

Development' tool was utilized to detect upregulated gene expression using microarray dataset in six developmental stages such as fruit ripening complete, ripening, fruit formation, flowering, inflorescence visible, and main shoot growth (https://genevestigator.com/gv/start /start.jsp). 'Anatomy' tool was subjected to evaluation of the expression potential of each gene using microarray OS-AFFY-RICE-0 dataset (http://www.genevestigator.ethz.ch).

\section{Gene Ontology (GO) Enrichment analysis and $K E G G$ pathway analysis}

Classification of DEGs by GO analysis using agriGO (http://systemsbiology.cau.edu.cn/agri GOv2/) indicates probable pathways captured by the responsive genes involved in fungi and oomycete infections. The GO database generated an overview of the functional classification of a list of AGI IDs which is used to identify the biological processes, molecular functions, and cellular component. For pathway evaluation of DEGs, String (http://string-db.org/) was utilized with $\mathrm{p}$-value cut-off of $\leq 0.05$ to visualize fungi and oomycete infections related to changes in the general metabolism.

\section{Analysis of the cis-elements}

Promoter regions of 51 genes were analyzed using PlantCare software (http://bioinformatics.psb. ugent.be/webtools/plantcare/html/). For each gene, $1500 \mathrm{bp}$ upstream of the transcription initiation region was considered as a promoter sequence. Investigation of cis-regulatory elements including transcription factors was done using the PlantCare database (Lescot et al., 2002). 
Table 1. Microarray data of gene expression induced by $P$. infestans and $C$. coccodes infections in tomato.

\begin{tabular}{|c|c|c|c|c|}
\hline Accession & Title & Source name & Cultivar & Tissue type \\
\hline GSE21376 & Healthy plants rep1 & $\begin{array}{l}\text { Tomato leaves from non- } \\
\text { inoculated plants }\end{array}$ & Money Marker & Leaves \\
\hline GSE21377 & Healthy plants rep2 & $\begin{array}{c}\text { Tomato leaves from non- } \\
\text { inoculated plants }\end{array}$ & Money Marker & Leaves \\
\hline GSE21378 & Healthy plants rep3 & $\begin{array}{c}\text { Tomato leaves from non- } \\
\text { inoculated plants }\end{array}$ & Money Marker & Leaves \\
\hline GSE21379 & Diseased plants rep1 & $\begin{array}{l}\text { Tomato leaves from } \\
\text { inoculated plants with } \\
\text { Phytophthora infestans }\end{array}$ & Money Marker & Leaves \\
\hline GSE21380 & Diseased plants rep2 & $\begin{array}{l}\text { Tomato leaves from } \\
\text { inoculated plants with } \\
\text { Phytophthora infestans }\end{array}$ & Money Marker & Leaves \\
\hline GSE21381 & Diseased plants rep3 & $\begin{array}{l}\text { Tomato leaves from } \\
\text { inoculated plants with } \\
\text { Phytophthora infestans }\end{array}$ & Money Marker & Leaves \\
\hline GSE21382 & Diseased plants rep4 & $\begin{array}{l}\text { Tomato leaves from } \\
\text { inoculated plants with } \\
\text { Phytophthora infestans }\end{array}$ & Money Marker & Leaves \\
\hline GSM546597 & $\begin{array}{l}\text { Tomato fruit wound } \\
\text { inoculation by } \\
\text { Colletotrichum coccodes }\end{array}$ & $\begin{array}{l}\text { Tomato breaker fruit } \\
\text { parenchyma cells }\end{array}$ & Hazera 1402 & Pericarp \\
\hline GSM546978 & $\begin{array}{l}\text { Tomato fruit wound } \\
\text { inoculation by } \\
\text { Colletotricbum coccodes } 2\end{array}$ & $\begin{array}{l}\text { Tomato breaker fruit } \\
\text { parenchyma cells }\end{array}$ & Hazera 1402 & Pericarp \\
\hline GSM546979 & $\begin{array}{l}\text { Tomato fruit wound } \\
\text { control }\end{array}$ & $\begin{array}{l}\text { Tomato breaker fruit } \\
\text { parenchyma cells }\end{array}$ & Hazera 1402 & Pericarp \\
\hline GSM546980 & $\begin{array}{c}\text { Tomato fruit wound } \\
\text { control } 2\end{array}$ & $\begin{array}{l}\text { Tomato breaker fruit } \\
\text { parenchyma cells }\end{array}$ & Hazera 1402 & Pericarp \\
\hline GSM546981 & $\begin{array}{c}\text { Tomato fruit ammonium } \\
\text { treatment }\end{array}$ & $\begin{array}{l}\text { Tomato breaker fruit } \\
\text { parenchyma cells }\end{array}$ & Hazera 1402 & Pericarp \\
\hline GSM546982 & $\begin{array}{c}\text { Tomato fruit ammonium } \\
\text { treatment } 2\end{array}$ & $\begin{array}{l}\text { Tomato breaker fruit } \\
\text { parenchyma cells }\end{array}$ & Hazera 1402 & Pericarp \\
\hline GSM546983 & $\begin{array}{c}\text { Tomato fruit PBS } \\
\text { control }\end{array}$ & $\begin{array}{l}\text { Tomato breaker fruit } \\
\text { parenchyma cells }\end{array}$ & Hazera 1402 & Pericarp \\
\hline GSM546984 & $\begin{array}{c}\text { Tomato fruit PBS } \\
\text { control } 2\end{array}$ & $\begin{array}{l}\text { Tomato breaker fruit } \\
\text { parenchyma cells }\end{array}$ & Hazera 1402 & Pericarp \\
\hline
\end{tabular}

\section{RESULTS AND DISCUSSION}

\section{Analysis of co-expressed genes in gene network}

The PPI network analysis of 51 genes revealed that the 11 co-expressed genes are involved in auxin metabolism (Tables 2 and 3). Plants are continuously subjected to pathogens in nature and, as a result, different mechanisms have been utilized to defend themselves. Auxin plays multiple roles in plant growth and development including their response to abiotic and biotic stresses (Kunkel and Harper, 2017). Auxin is one of the up-regulated genes involved in the coexpressed network enhancing auxin level which in turn can antagonize defense responses in some plant- pathogen interactions (Kunkel and Harper, 2017). On the other hand, auxin can also act as a signaling molecule to induce virulence genes required in pathogenesis (Chandler, 2016). It has been reported that auxin is decreased notably upon drought but increased in response to cold and heat stresses in rice and pathogen infection in Arabidopsis thaliana (Hout et al., 2014; Ramegowda et al., 2015). Transcriptional regulators like Auxin/Indole-Acetic Acid (Aux/IAAs), Auxin Response Factors (ARFs), and TOPLESS 
proteins (TPS) can regulate auxin level in cellspecific transcription (Zouine et al., 2014). It is concluded that auxin might be implicated in pathogen infection response through ARFs (Sun et al., 2015). Similar findings offer that the regulation of auxin signaling could be critical in defense response through the regulation of the expression of ARF gene in tomato (Kunkel and Harper, 2017). Solyc06g007510.3 is one of the responsive genes involved during plant-pathogen interaction. Findings of a research suggested that Solyc06g007510.3 is selectively expressed during hormone treatment and pathogen infection (Sharma and Bhatt, 2017).

Table 2. Characterized key genes in response to fungi and oomycete infections.

\begin{tabular}{|c|c|c|c|}
\hline No. & Gene ID & Description or functional genes & Location \\
\hline 1 & Solyc02g077390.2 & Compound inflorescence, $\mathrm{S}$ gene & ch2:42336107..42338039 \\
\hline 2 & Solyc02g081670.1 & DOT & ch2:45542385..45543752 \\
\hline 3 & Solyc06g007510.3 & Ubiquitin-conjugating enzyme & $\operatorname{ch} 6: 48411762 . .48416262$ \\
\hline 4 & Solyc07g062840.3 & Goblet & $\operatorname{ch} 7: 65615837 . .65618073$ \\
\hline 5 & Solyc11g072600.2 & AP2 transcription factor SlAP2d & $\operatorname{ch} 11: 56068300-56071320$ \\
\hline 6 & Solyc02g064960.3 & AP2 transcription factor SlAP2b & $\operatorname{ch} 2: 36641329-36645265$ \\
\hline 7 & Solyc02g083950.3 & WUSCHEL-related homeobox-containing protein 4,WUS & $\operatorname{ch} 2: 47744436-47748006$ \\
\hline 8 & Solyc11g013310.2 & LAX3 protein & ch11:6272690..6272875 \\
\hline 9 & Solyc10g076790.2 & LAX4 protein & $\operatorname{ch} 10: 59843582-59848957$ \\
\hline 10 & Solyc03g005355.1 & IAA1 & ch3:210025-212319 \\
\hline 11 & Solyc05g008850.3 & Aux/IAA & ch5:3078325-3079636 \\
\hline
\end{tabular}

Ubiquitin-ligase degrades transcriptional repressor Aux/IAA and then releases auxin response factor or ARF to regulate the transcription of auxin-responsive genes (Woodward and Bartel, 2005). LAX3 and LAX4 are transporters of auxin and auxin-inducible genes in which their expressions are downregulated dramatically under the stress (Péret $e t$ al., 2013). In this study, Solyc02g077390.2 encoded a transcription factor associated to a gene called wus gene which were co-expressed in the gene network. Wus gene expression is regulated by abiotic stress and plant hormones. Wus gene was another coexpressed gene in the present network which seemed to control auxin signaling output at all levels and places (Figure 1). There is another report that wus gene can regulate the expression of a large number of genes implicated in auxin biosynthesis, transport, perception, and response. Also, it has been reported that in SAM, wus protein can act as a transcriptional activator or repressor of auxin signaling component on the regulatory environment. In Arabidopsis, wus gene seems to act both upstream and downstream of the key ARF transcription factors due to reduced auxin under stress (Ma et al., 2018). Functional studies in NAM/NAC have revealed that many of the NAC TFs regulate immune responses in plants. Knockout of OsNAC6 lead to fungi penetration of powdery mildew in rice (Jensen et al., 2008). AP2 is involved in several key steps in plant development and response to cold, heat, drought, and pathogen infections through different hormones related to signal transduction pathways such as ethylene, cytokinin and jasmonate (Rashotte et al., 2010; Hu et al., 2013).

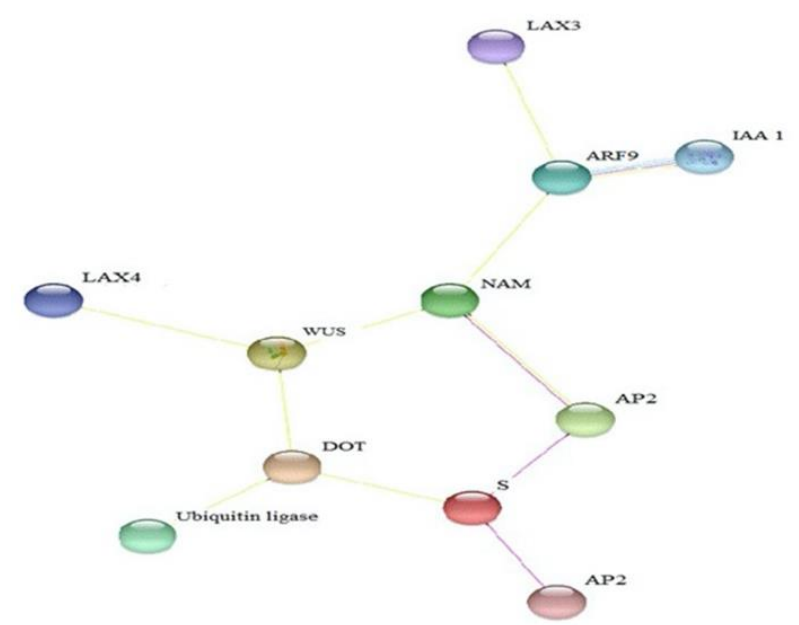

Figure 1. Interactions of responsive genes to both fungi and oomycete infections in tomato genotypes where each node and edge represents a protein and interaction, respectively. The web based tool "String" (http://string-db.org/) was utilized to predict the interactions. 
Table 3. Description of 51 genes in response to oomycete and fungi infections in tomato.

\begin{tabular}{|c|c|c|c|c|c|}
\hline No. & Gene ID & Description & No. & Gene ID & Description \\
\hline 1 & Solyc $07 g 005330.3$ & Beta-glucosidase 08 & 27 & Solyc02g064960.3 & $\begin{array}{c}\text { AP2 transcription } \\
\text { factor S1AP2b, AP2b }\end{array}$ \\
\hline 2 & Solyc $02 \mathrm{~g} 077390.2$ & $\begin{array}{l}\text { S gene, compound } \\
\text { inflorescence }\end{array}$ & 28 & Solyc06g075510.3 & $\begin{array}{l}\text { AP2 transcription } \\
\text { factor SlAP2e }\end{array}$ \\
\hline 3 & Solyc02g081670. & DOT & 29 & Solyc11g013810.2 & Nitrate reductase \\
\hline 4 & Solyc06g007510.3 & $\begin{array}{l}\text { Ubiquitin-conjugating } \\
\text { enzyme }\end{array}$ & 30 & Solyc02g083950.3 & WUS \\
\hline 5 & Solyc $06 g 082600.3$ & $\begin{array}{l}\text { Ubiquitin-conjugating } \\
\text { enzyme }\end{array}$ & 31 & Solyc06g076410.3 & $\begin{array}{l}\text { C-4 methyl sterol } \\
\text { oxidase }\end{array}$ \\
\hline 6 & Solyc07g062840.3 & NAM & 32 & Solyc01g097440.3 & N-glycanase \\
\hline 7 & Solyc08g081010.3 & GSH1 & 33 & Solyc09g014380.3 & LAX1 protein \\
\hline 8 & Solyc01g109880.3 & $\mathrm{bZIP}$ & 34 & Solyc01g111310.3 & LAX2 protein \\
\hline 9 & Solyc $04 g 050930.3$ & Violaxanthin de-epoxidase & 35 & Solyc11g013310.2 & LAX3 protein \\
\hline 10 & Solyc $08 g 063080.3$ & $\begin{array}{c}\text { UDP-sulfoquinovose } \\
\text { synthase } \\
\end{array}$ & 36 & Solyc10g076790.2 & LAX4 protein \\
\hline 11 & Solyc07g066580.3 & Sulfurtransferase & 37 & Solyc10g055260.2 & LAX5 protein \\
\hline 12 & Solyc $08 g 005680.3$ & Dimethylallylcistransferase & 38 & Solyc05g049970.3 & $\begin{array}{c}\text { Mitogen-activated } \\
\text { protein kinase } 6 \\
\text { (MAPK6) } \\
\end{array}$ \\
\hline 13 & Solyc $04 g 008380.3$ & $\begin{array}{c}\text { GAGA-binding } \\
\text { transcriptional activator }\end{array}$ & 39 & Solyc08g081495.1 & MAPK7 \\
\hline 14 & Solyc08g076230.1 & $\begin{array}{c}\text { GAGA-binding } \\
\text { transcriptional activator }\end{array}$ & 40 & Solyc07g062080.3 & MAPK11 \\
\hline 15 & Solyc04g081170.3 & $\begin{array}{c}\text { GAGA-binding } \\
\text { transcriptional activator }\end{array}$ & 41 & Solyc07g056350.3 & MAPK12 \\
\hline 16 & Solyc01g079620.3 & MYB12 & 42 & Solyc01g080240.3 & MAPK13 \\
\hline 17 & Solyc07g066480.3 & $\begin{array}{l}\text { Molybdenum cofactor } \\
\text { sulfurase }\end{array}$ & 43 & Solyc04g007710.3 & MAPK14 \\
\hline 18 & Solyc06g073190.3 & Fructokinase-2 & 44 & Solyc12g040680.2 & MAPK16 \\
\hline 19 & Solyc07g064680.3 & Autophagy-related protein & 45 & Solyc05g008020.3 & MAPK15 \\
\hline 20 & Solyc $08 g 078820.3$ & Autophagy-related protein & 46 & Solyc03g005355.1 & IAA1 \\
\hline 21 & Solyc $08 \mathrm{~g} 078320.3$ & $\begin{array}{l}\text { Ubiquitin-protein ligases, } \\
\text { E2 enzyme }\end{array}$ & 47 & Solyc05g008850.3 & Aux/IAA \\
\hline 22 & Solyc09g092170.2 & Beta-galactosidase & 48 & Solyc02g091840.3 & $\begin{array}{c}\text { Leucine rich repeat } \\
\text { receptor protein kinase } \\
\text { CLAVATA1 }\end{array}$ \\
\hline 23 & Solyc03g119770.3 & TCP9 & 49 & Solyc04g-056640.1 & RLP \\
\hline 24 & Solyc06g069240.2 & TCP8 & 50 & Solyc03g059490.1 & $\begin{array}{c}\text { Receptor like kinase, } \\
\text { RLK }\end{array}$ \\
\hline 25 & Solyc02g093150.3 & $\begin{array}{l}\text { AP2 transcription factor } \\
\text { S1AP2c }\end{array}$ & 51 & Solyc $05 \mathrm{~g} 023760.3$ & $\begin{array}{l}\text { Receptor like protein } \\
\text { kinase SOL2 }\end{array}$ \\
\hline 26 & Solyc11g072600.2 & $\begin{array}{l}\text { AP2 transcription factor } \\
\text { SIAP2d }\end{array}$ & & & \\
\hline
\end{tabular}

\section{In silico analysis of DEGs expression}

Meta-analysis of Genevestigator microarray dataset was performed on S. lycopersicum DEGs (Figure 2). Solyc06g007510.3 was the highest expressed gene in almost all stages of developmental stages such as fruit ripening complete, ripening, fruit formation, flowering, inflorescence visible, and main shoot growth whereas, Solyc05g008850.3 showed the lowest expression during the all stages. Solyc07g066580.3 and Solyc08g063080.3 were slightly up-regulated in all developmental stages in tomato (Figure 2). In course of the inflorescence visible stage most of genes showed almost same level of expression. Expression of all genes were maximal during all the stages of main shoot growth whereas, expression of these genes were minimal during the fruit formation and flowering stages.

Anatomy expression profile showed that the number of down-regulated DEGs in generative cells was higher than the up-regulated DEGs, while the opposite occurred in sympodial inflorescence meristem, shoot apex, and floral meristem under fungi and oomycete stresses. 
Solyc05g008850.3 was down regulated during all the stage-specific tissues such as hypodermis, outer epidermis, parenchyma, seed, locular tissue, endocarp, leaf, flower, columella, generative cell, radical pericarp, ovary wall, fruit, placenta, pericarp, leaflet, inner pericarp, ovule, callus, pistil, placenta, vascular tissue, roots, floral meristem, sympodial inflorescence meristem, and shoot apex. ARF plays a critical role in the transcriptional activation or repression of auxinresponsive genes or IAA through direct binding to their promoters (Bouzroud et al., 2018). Auxin is implicated in plant developmental processes and response to environmental stresses (Liu et al., 2014). It has been reported that the auxin level was reduced notably upon drought condition but was enhanced in response to heat in rice and during pathogen infections in Arabidopsis (Schmeiz et al., 2004; Du et al., 2013). Based on another study, auxin is as an active player in plant defense against pathogens (Navarro et al., 2006). Our findings agreed with Bouzroud et al (2018) and Saidi and Hajibarat (2019) that suggested auxin could be implicated in pathogen infections through ARFs.

Solyo6g007510.3 had the highest expression in all of tissue specific (Figure 3). The ubiquitindependent protein degradation pathway is implicated in hormone regulation, senescence, morphogenesis, and pathogen defense (Devoto et al., 2003). Previous studies showed that ubiquitination can also play a critical role in plant tolerance against different biotic and abiotic stresses (Zhou et al., 2010; Jeon et al., 2012). It has been reported that the expression of Solyc06g007510.3 genes was observed in different tissues of tomato genotypes, a finding which is in agreement to our results (Sharma and Bhatt, 2017). A recent study revealed that the Solyc06g007510.3 was positively regulating immunity due to pathogen attack and hormone treatment in tomato (Hamera et al., 2014). E2 ubiquitin-conjugating enzyme was expressed in response to ABA and auxin hormone (Sharma and Bhatt, 2017).

\section{Gene Ontology enrichment analysis}

Gene ontology analysis revealed that pathogenresponsive genes were preferentially involved in the biological processes including metabolic and cellular processes, cellular metabolic process, organic substance metabolic process, cellular biosynthetic process, organic substance biosynthetic process, primary metabolic process, and cellular macromolecule metabolic process which acted as indices of significant biological pathways underlying the fungi and oomycetes responses of plants (Figure 4). Similar results were recently observed for tomato- $X$. perforans interaction (Du et al., 2015). The cellular component is involved in intracellular membranebounded organelle and chloroplast. The molecular function is related to binding, ion binding, organic cyclic compound binding, heterocyclic compound binding, and catalytic activity (Figure 4). Our results revealed a similar activation of the basic response related genes in fungi and oomycete infections (Tan et al., 2015). These pathways can overlap with tomato responses to pathogens which agrees with the genes involved in bacterial and fungal tolerance in tomato (McCormick et al.,1986; Tan et al., 2013).

\section{KEGG analysis of DEGs}

To characterize and evaluate the active biological pathways of the identified DEGs, gene classification was performed on the basis of KEGG analysis (Kanehisa et al., 1999). Only significant pathway categories were selected and listed in Figure 5. The pathways involving the highest number of DEGs were plant hormone signal transduction, amino sugar and nucleotide sugar metabolism, autophagy, and cysteine and methionine metabolism. Another survey has reported that the genes responding to $V$. dabliae in tomato include hormone signal transduction, glutathione metabolism, and phenylalanine metabolism which are similar to those major pathways implicated in plant and pathogen interactions (Sun et al., 2014). Therefore, the DEGs implicated in these pathways can be considered as gene candidates for genetic engineering and breeding programs for tomato genetic improvements for fungi and oomycete infections. 

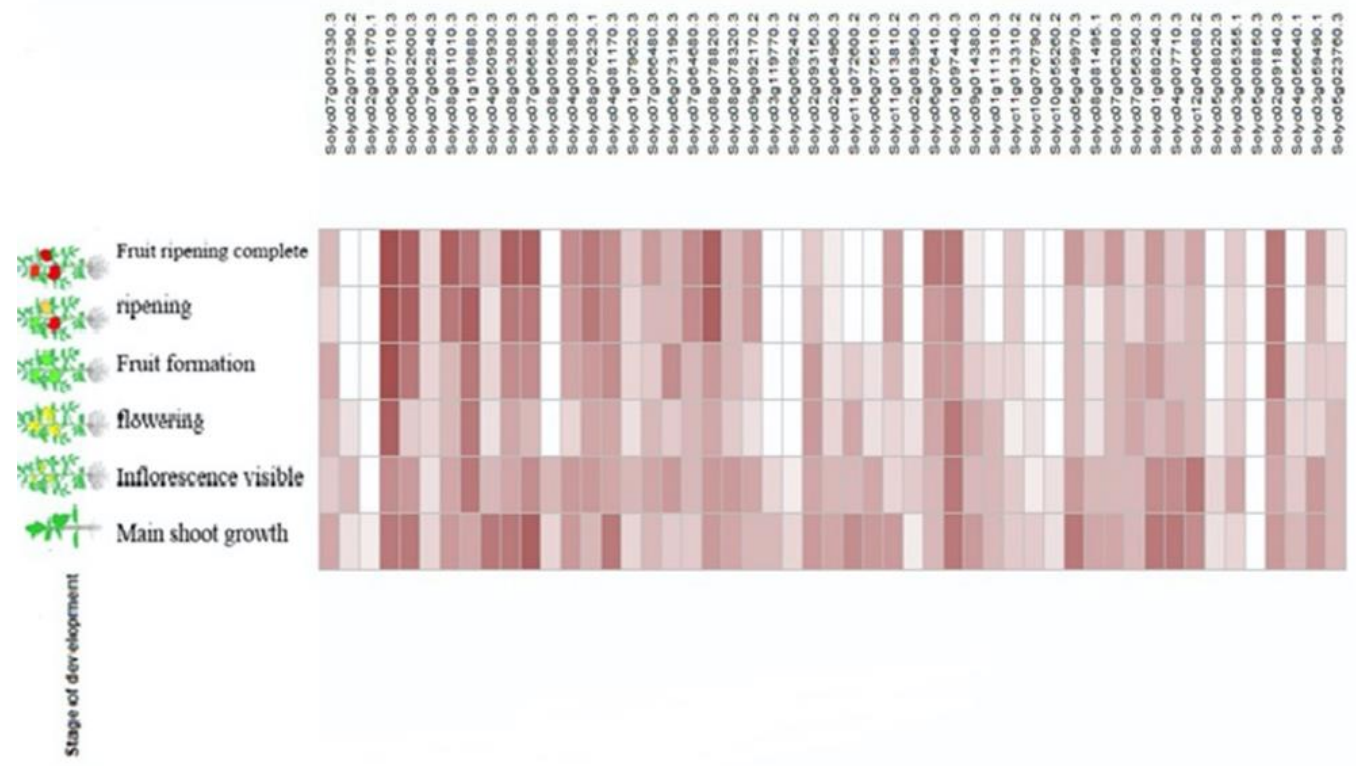

Figure 2. Heat map results of differentially expressed genes in the microarray experiment. Each row represented log2-fold change of the relative gene expression. Up and down-regulated expression genes are represented by red and white colors, respectively.

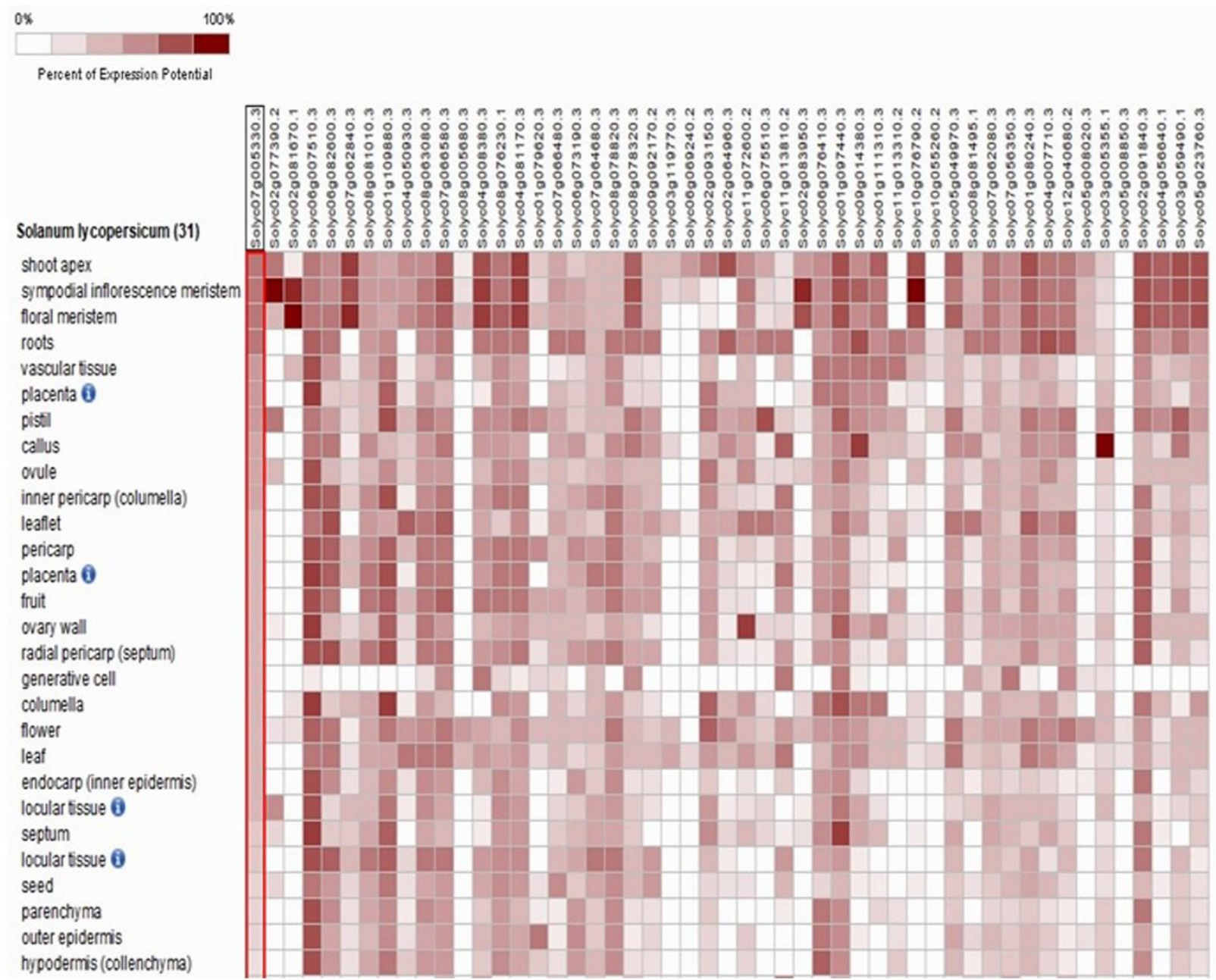

Figure 3. Anatomy expression profiles of responsive genes at different developmental stages under fungi and oomycete infections in S.lycopersicum. 


\section{Gene function classification}

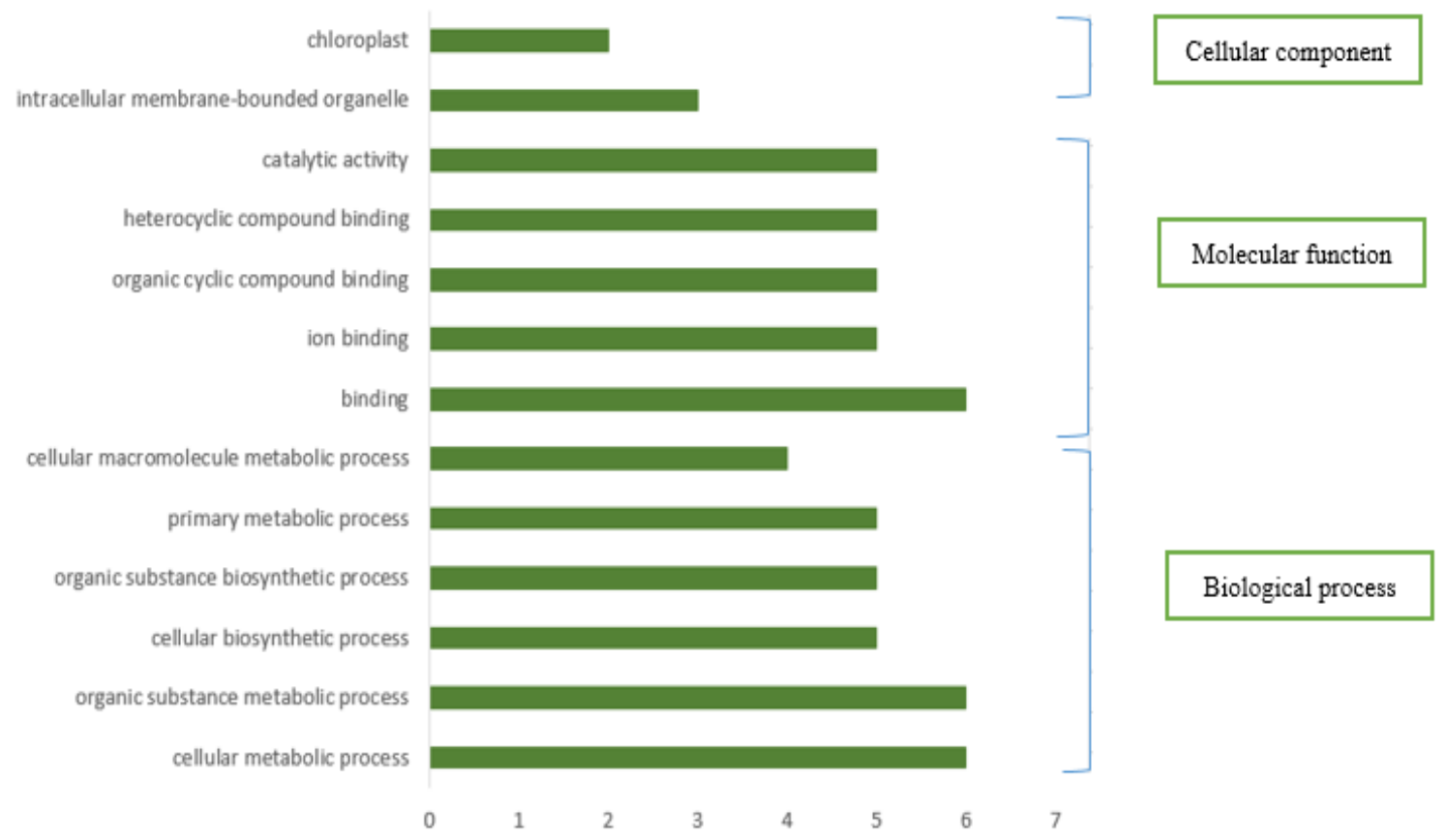

Figure 4. Gene Ontology (GO) categories of DEGs based on molecular function, biological processes, and cellular component in response to both fungi and oomycete infections in Money Marker and Hazera 1402 tomato genotypes.

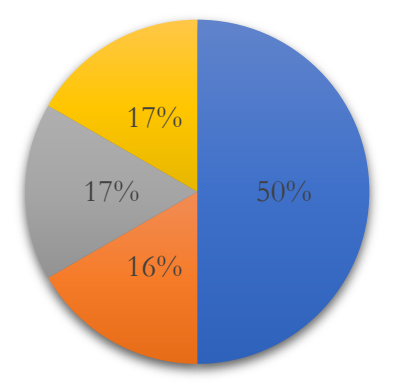

- Plant hormone signal transduction

• Cysteine and methionine metabolism
- Autophagy - other

$\square$ Amino sugar and nucleotide sugar metabolism

Figure 5. Diagram of significantly enriched KEGG pathways of DEGs by fungi and oomycete infections.

\section{Analysis of cis-regulatory elements in the promoter regions}

In order to obtain more information regarding the regulatory elements involved in response to signaling molecules, their promoter regions were analyzed for frequency and types of cis-elements. The characterized cis-regulatory elements (CREs) included the seven most common CREs found in the promoter sequences of the -1 $<$ DEGs $<1$ fold change (CAAT-box, TATAbox, TGACG motif, MYB, MYC, ABRE, and GBox). CREs are binding sites for transcription factors involved in regulation of transcription. Surveys on association of CREs provide clearer understanding of the promoter function and help to provide better insight about regulation of gene 
expression (Hernandez-Garcia and Finer, 2014; Saidi and Hajibarat, 2019). Description of the first 12 most frequently occurring cis-elements of the total detected elements is provided in Figure 6. Our analysis showed that among CREs, CATT-box and TATA-box were the highest number of CRE whereas, the least number of CRE was observed in CGTCA-motif genes under fungi and oomycete infections, respectively.

MYB proteins include the largest family of TFs in plants and are involved in gene expression related to development, disease resistance, and abiotic stress tolerance ( $\mathrm{Li}$ et al., 2009). In Arabidopsis, AtMYB96 mediated ABA signals as a tolerance mechanism to pathogen infections using inducing salicylic acid biosynthesis (Nagaraju et al., 2019). A report has shown that expression of some MYB family members are regulated by auxin (Shin et al., 2007). MYC transcription factors are major transcriptional regulators in the expression of jasmonate (JA)responsive genes, positive regulator in wound resistance genes and negative regulators during the expression of pathogen defense genes (Van et al., 2009). MYB and WRKY can activate the expression of MYC transcription factor under stress and as a result MYC activates the transcription of JAZ protein. JAZ protein quickly aids to promote the release and activation of MYC. ABRE can induce ABA expression which in turn acts as a binding site for bZIP family transcription factors (Lenka et al., 2009). ABRE motifs, bZIP, AuxRE, MYC and MYB recognition sites were found to be significantly enriched in the auxin-responsive promoters from Arabidopsis and rice (Berendzen et al., 2012; Abe et al., 2003).

Recently, it has been pointed out that MYB Related Elements (MREs) MREs, bZIP Response Elements (ZREs), and ARF have to function together as potential quantitative elements in auxin-mediated transcription in Arabidopsis and rice (Berendzen et al., 2012; Abe et al., 2003). Based on another study, auxin level and expression act as the primary regulator of pathogen stress response in fungal pathogen infected plants (Yin et al., 2014). Our results can suggest that MYB, MYC, G-box, and ABRE have key roles in auxin signaling for pathogeninducible genes. This analysis confirmed that specific and composite motif containing AuxREs, ZREs, G-box related MYC element, are importantly enriched in the promoters of auxin inducible genes and in some auxinregulated gene families (Berendzen et al., 2012). Both DNA motifs (G-box and TGACG motif) are found in several plant promoters bZIP proteins (Saidi and Hajibarat, 2019). G-box, also known as ABRE (ABA-responsive element), is a binding site for bZIP proteins which has been identified as binding proteins (Hatton et al., 1995). BZIP, bHLH, and G-box enhance the possibility of being co-regulated by other transcription factors to regulate gene expression under pathogen infections (Saidi and Hajibarat, 2018; Liu et al., 2017). The TGACG motif, known as 'as1 element', is also involved in MeJA response which is present in the promoter of some plant genes activated during defense under pathogen infections (Zhang et al., 1999).

\section{CONCLUSION}

In this study, in silico analysis of DEGs tomato was performed during fungi and oomycete infections, and the presence of different types of CREs were identified. Consequently, analysis of gene network of co-expressed genes, expression patterns in stage specific-tissue, and expression in stages of development were performed using bioinformatics tools. Our findings showed that 12 important CREs were implicated in auxin management to minimize damage in tomato. Most co-expressed genes were involved in synthesis, metabolism, and degradation of auxin which in turn controls auxin concentration under fungi and oomycete infections. Auxin was down and up regulated by ARFs and E2-enzymes during all staged of specific tissues, respectively. Thus, these up or down regulations of auxin can make it possible to prevent pathogen growth through regulation of auxin concentration. Our findings suggested that genes involved in auxin signaling pathway can provide a better overview of the transcriptome changes of tomato cultivars under pathogen infections, which can provide insights as to how tomato evolved to adopt with pathogen infections. 


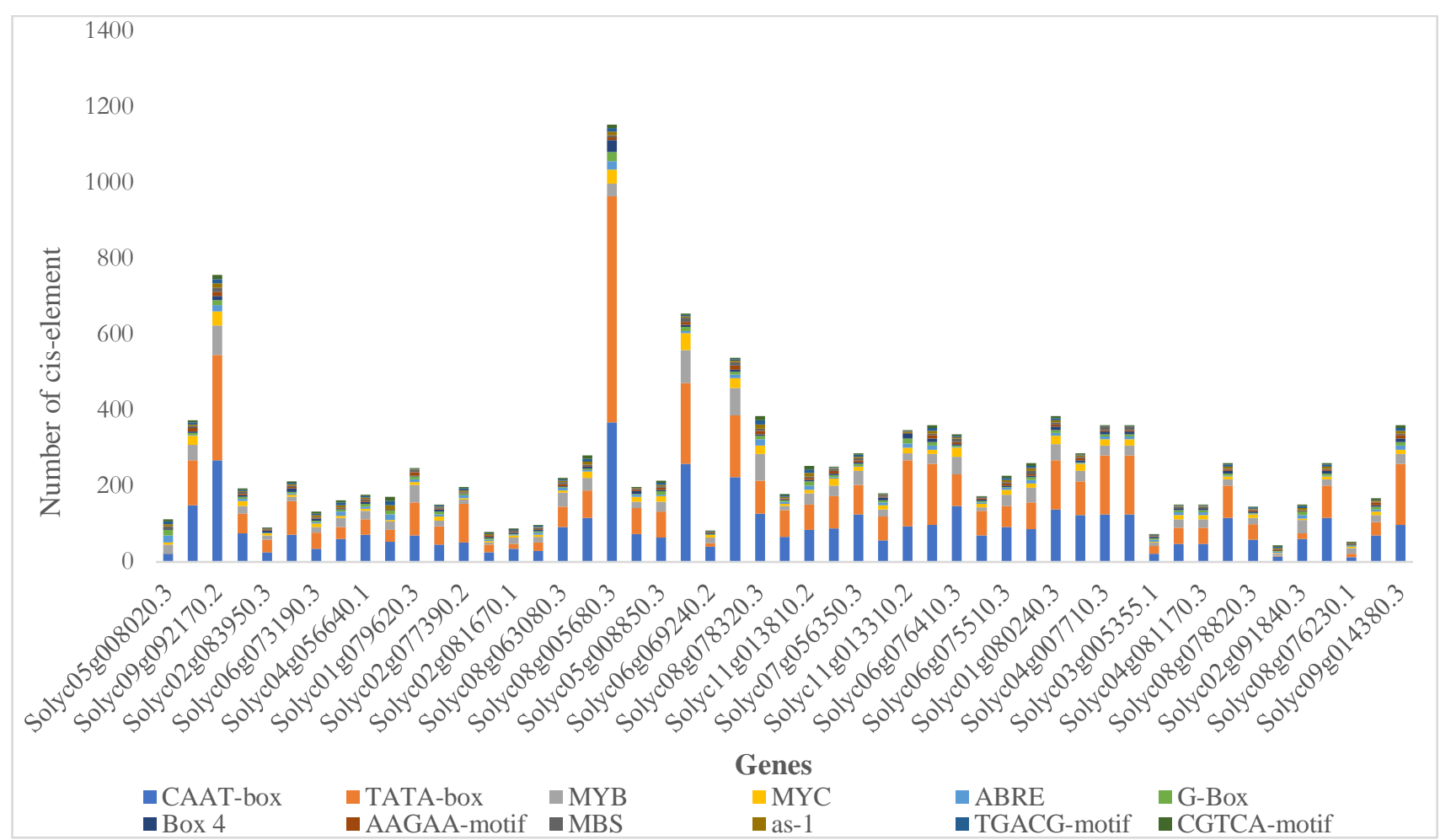

Figure 6. Histogram showing the frequencies of responsive genes of CREs under fungi and oomycete infections in S.lycopersicum.

\section{REFERENCES}

Abe, H., Urao, T., Ito, T., Seki, M., Shinozaki, K., \& YamaguchiShinozaki, K. 2003. Arabidopsis AtMYC2 (bHLH) and AtMYB2 (MYB) function as transcriptional activators in abscisic acid signaling. The Plant Cell 15(1): 63-78.

Barr, R., Dreeben, R., \& Wiratchai, N. 1983. How schools work. Chicago: University of Chicago Press.

Berendzen, K. W., Weiste, C., Wanke, D., Kilian, J., Harter, K., \& Dröge-Laser, W. 2012. Bioinformatic cis-element analyses performed in Arabidopsis and rice disclose bZIP-and MYB-related binding sites as potential AuxRE-coupling elements in auxin-mediated transcription. BMC Plant Biology 12(1): 125.

Bouzroud, S., Gouiaa, S., Hu, N., Bernadac, A., Mila, I., Bendaou, N., \& Zouine, M. 2018. Auxin response factors (ARFs) are potential mediators of auxin action in tomato response to biotic and abiotic stress (Solanum lycopersicum). PloS One 13(2): e0193517.

Brumlop, S. \& Finckh, M. R. 2011. Applications and potentials of marker assisted selection (MAS) in plant breeding. BfNSkripten (Bundesamt für Naturschutz) 298.

Chandler, J. W. 2016. Auxin response factors. Plant, Cell \& Environment 39(5): 1014-1028.

Devoto, A. \& Turner, J. G. 2003. Regulation of jasmonatemediated plant responses in Arabidopsis. Annals of Botany 92(3): 329-337.

Du, H., Liu, H., \& Xiong, L. 2013. Endogenous auxin and jasmonic acid levels are differentially modulated by abiotic stresses in rice. Frontiers in Plant Science 4: 397.

Du, H., Wang, Y., Yang, J., \& Yang, W. 2015. Comparative transcriptome analysis of resistant and susceptible tomato lines in response to infection by Xanthomonas perforans race T3. Frontiers in Plant Science 6: 1173.

Fentik, D. A. 2017. Review on genetics and breeding of tomato (Lycopersicon esculentum Mill.). Advances in Crop Science and Technology 5(5): 306.

Gudero, G., Hussien, T., Dejene, M., \& Biazin, B. 2018. Integrated management of tomato late blight [Phytophthora infestans (Mont.) de Bary] through host plant resistance and reduced frequency of fungicide in Arbaminch areas, Southern Ethiopia. Journal of Biology, Agriculture and Healthcare 8(9): 94109.

Hamera, S., Mural, R. M., Liu, Y., \& Zeng, L. 2014. The tomato ubiquitin-conjugating enzyme variant Suv, but not SIUev1C and SIUev1D regulates Fen-mediated programmed cell death in Nicotiana benthamiana. Plant Signaling \& Behavior 9(10): e973814.

Hatton, D., Sablowski, R., Yung, M. H., Smith, C., Schuch, W., \& Bevan, M. 1995. Two classes of cis sequences contribute to tissue-specific expression of a PAL2 promoter in transgenic tobacco. The Plant Journal 7(6): 859-876.

Hernandez-Garcia, C. M. \& Finer, J. J. 2014. Identification and validation of promoters and cis-acting regulatory elements. Plant Science 217:109-119.

Huot, B., Yao, J., Montgomery, B. L., \& He, S. Y. 2014. Growthdefense tradeoffs in plants: a balancing act to optimize fitness. Molecular Plant 7(8): 1267-1287.

Hu, Y., Jiang, L., Wang, F., \& Yu, D. 2013. Jasmonate regulates the inducer of $\mathrm{CBF}$ expression-c-repeat binding factor/DRE binding factor1 cascade and freezing tolerance in Arabidopsis. The Plant Cell 25(8): 2907-2924.

Jensen, M. K., Hagedorn, P. H., De Torres-Zabala, M., Grant, M. R., Rung, J. H., Collinge, D. B. \& Lyngkjaer, M. F. 2008. Transcriptional regulation by an NAC (NAM-ATAF1, 2CUC2) transcription factor attenuates ABA signalling for 
efficient basal defense towards Blumeria graminis $\mathrm{f}$. sp. hordei in Arabidopsis. The Plant Journal 56(6): 867-880.

Jeon, E. H., Pak, J. H., Kim, M. J., Kim, H. J., Shin, S. H., Lee, J. H., \& Chung, Y. S. 2012. Ectopic expression of ubiquitinconjugating enzyme gene from wild rice, $\mathrm{OgUBC} 1$, confers resistance against UV-B radiation and Botrytis infection in Arabidopsis thaliana. Biochemical and Biophysical Research Communications 427(2): 309-314.

Kanehisa, M. \& Goto, S. 2000. KEGG: kyoto encyclopedia of genes and genomes. Nucleic Acids Research 28(1): 27-30.

Kunkel, B. N. \& Harper, C. P. 2017. The roles of auxin during interactions between bacterial plant pathogens and their hosts. Journal of Experimental Botany 69(2): 245-254.

Lenka, S. K., Lohia, B., Kumar, A., Chinnusamy, V., \& Bansal, K. C. 2009. Genome-wide targeted prediction of ABA responsive genes in rice based on over-represented cismotif in co-expressed genes. Plant Molecular Biology 69(3): 261-271.

Lescot, M., Déhais, P., Thijs, G., Marchal, K., Moreau, Y., Van de Peer, Y., \& Rombauts, S. 2002. PlantCARE, a database of plant cis-acting regulatory elements and a portal to tools for in silico analysis of promoter sequences. Nucleic Acids Research 30(1): 325-327.

Li, L., Yu, X., Thompson, A., Guo, M., Yoshida, S., Asami, T., \& Yin, Y. 2009. Arabidopsis MYB30 is a direct target of BES1 and cooperates with BES1 to regulate brassinosteroidinduced gene expression. The Plant Journal 58(2): 275-286.

Liu L, Guo G, Wang Z, Ji H, Mu F, Li X. 2014. Auxin in Plant Growth and Stress Responses. In: Tran L-SP, Pal S, editors. Phytohormones: A Window to Metabolism, Signaling and Biotechnological Applications. Springer New York. pp. 1-35.

Liu, L., Zhang, X., Chen, F., Mahi, A. A. E., Wu, X., Chen, Q., \& Fu, Y. F. 2017. Analysis of promoter activity reveals that GmFTL2 expression differs from that of the known Flowering Locus $\mathrm{T}$ genes in soybean. The Crop Journal 5(5): 438-448.

Ma, Y., Miotk, A., Sutikovic, Z., Medzihradszky, A., Wenzl, C., Ermakova, O., \& Galvan-Ampudia, C. S. 2018. WUSCHEL acts as a rheostat on the auxin pathway to maintain apical stem cells in Arabidopsis. bioRxiv: 468421.

McCormick, S., Niedermeyer, J., Fry, J., Barnason, A., Horsch, R. \& Fraley, R. 1986. Leaf disc transformation of cultivated tomato (L. esculentum) using Agrobacterium tumefaciens. Plant Cell Reports 5: 81-84.

McLeod, A., Smart, C.D. \& Fry, W.E. 2004. Core promoter structure in the oomycete Phytophthora infestans. Eukaryotic Cell 3(1):91-99.

Miller, M. B. \& Tang, Y. W. 2009. Basic concepts of microarrays and potential applications in clinical microbiology. Clinical Microbiology Reviews 22(4): 611-633.

Nagaraju, M., Reddy, P. S., Kumar, S. A., Kumar, A., Rajasheker, G., Rao, D. M., \& Kishor, P. K. 2019. Genome-wide identification and transcriptional profiling of small heat shock protein gene family under diverse abiotic stress conditions in Sorghum bicolor (L.). International Journal of Biological Macromolecules: 1-39.

Navarro, L., Dunoyer, P., Jay, F., Arnold, B., Dharmasiri, N., Estelle, M., \& Jones, J. D. 2006. A plant miRNA contributes to antibacterial resistance by repressing auxin signaling. Science 312(5772): 436-439.

Nowicki, M., Foolad, M. R., Nowakowska, M. \& Kozik, E. U. 2012. Potato and tomato late blight caused by Phytophthora infestans: an overview of pathology and resistance breeding. Plant Disease 96(1): 4-17.

Péret, B., Middleton, A. M., French, A. P., Larrieu, A., Bishopp, A., Njo, M., \& Casimiro, I. 2013. Sequential induction of auxin efflux and influx carriers regulates lateral root emergence. Molecular Systems Biology 9(1).
Prusky, D., Kobiler, I., Miyara, I. \& Alkan, N. 2009. Fruit diseases. The mango, botany, production and uses. pp. $210-$ 231.

Raiola, A., Rigano, M. M., Calafiore, R., Frusciante, L., \& Barone, A. 2014. Enhancing the health-promoting effects of tomato fruit for biofortified food. Mediators of inflammation, 2014.

Ramegowda, V. \& Senthil-Kumar, M. 2015. The interactive effects of simultaneous biotic and abiotic stresses on plants: mechanistic understanding from drought and pathogen combination. Journal of Plant Physiology 176: 47-54.

Rashotte, A. M., \& Goertzen, L. R. 2010. The CRF domain defines cytokinin response factor proteins in plants. BMC Plant Biology 10(1): 74.

Saidi, A. \& Hajibarat, Z. 2018. In silico Analysis of floral MADSbox gene in Brachypodium distachyon. Biobature: 366-375.

Saidi, A. \& Hajibarat, Z. 2019. Characterization of cis-elements in hormonal stress-responsive genes in Oryza sativa. Asia-Pacific Journal of Molecular Biology and Biotechnology 27(1) : 95-102.

Schmelz, E. A., Engelberth, J., Tumlinson, J. H., Block, A., \& Alborn, H. T. 2004. The use of vapor phase extraction in metabolic profiling of phytohormones and other metabolites. The Plant Journal 39(5): 790-808.

Senan, S., Kizhakayil, D., Sasikumar, B., \& Sheeja, T. E. 2014. Methods for development of microsatellite markers: an overview. Notulae Scientia Biologicae 6(1): 1-13.

Sharma, B. \& Bhatt, T. K. 2017. Genome-wide identification and expression analysis of E2 ubiquitin-conjugating enzymes in tomato. Scientific Reports 7(1): 8613.

Shin, R., Burch, A. Y., Huppert, K. A., Tiwari, S. B., Murphy, A. S., Guilfoyle, T. J., \& Schachtman, D. P. 2007. The Arabidopsis transcription factor MYB77 modulates auxin signal transduction. The Plant Cell 19(8): 2440-2453.

Stam, R., Mantelin, S., McLellan, H., \& Thilliez, G. 2014. The role of effectors in non-host resistance to filamentous plant pathogens. Frontiers in Plant Science 5: 582.

Stępień, Ł., Mohler, V., Bocianowski, J., \& Koczyk, G. 2007. Assessing genetic diversity of Polish wheat (Triticum aestivum) varieties using microsatellite markers. Genetic Resources and Crop Evolution 54(7): 1499-1506.

Sun, H., Wei, J., Zhang, J., \& Yang, W. 2014. A comparison of disease severity measurements using image analysis and visual estimates using a category scale for genetic analysis of resistance to bacterial spot in tomato. European Journal of Plant Pathology 139(1): 125-136.

Sun, X., Xu, L., Wang, Y., Yu, R., Zhu, X., Luo, X., ... \& Liu, L. 2015. Identification of novel and salt-responsive miRNAs to explore miRNA-mediated regulatory network of salt stress response in radish (Raphanus sativus L.). BMC Genomics 16(1): 197.

Szklarczyk, D., Morris, J. H., Cook, H., Kuhn, M., Wyder, S., Simonovic, M., \& Jensen, L. J. 2016. The STRING database in 2017: quality-controlled protein-protein association networks, made broadly accessible. Nucleic Acids Research: gkw937.

Tan, S., Jiang, Y., Song, S., Huang, J., Ling, N., Xu, Y., \& Shen, Q. 2013. Two Bacillus amyloliquefaciens strains isolated using the competitive tomato root enrichment method and their effects on suppressing Ralstonia solanacearum and promoting tomato plant growth. Crop Protection 43: 134-140.

Tan, G., Liu, K., Kang, J., Xu, K., Zhang, Y., Hu, L., \& Li, C. 2015. Transcriptome analysis of the compatible interaction of tomato with Verticillium dabliae using RNAsequencing. Frontiers in Plant Science 6: 428.

Tester, M., \& Langridge, P. 2010. Breeding technologies to increase crop production in a changing world. Science 327(5967): 818-822.

Tyler, B. M. \& Rouxel, T. 2012. Effectors of fungi and oomycetes: their virulence and avirulence functions and translocation 
from pathogen to host cells. Molecular Plant Immunity:123167.

Van Verk, M. C., Gatz, C., \& Linthorst, H. J. 2009. Transcriptional regulation of plant defense responses. Advances in Botanical Research 51: 397-438.

Wirthmueller, L., Maqbool, A. \& Banfield, M.J. 2013. On the front line: structural insights into plant-pathogen interactions. Nature Reviews Microbiology 11(11): 761.

Woodward, A. W., \& Bartel, B. 2005. Auxin: regulation, action, and interaction. Annals of Botany 95(5): 707-735.

Yin, C., Park, J. J., Gang, D. R., \& Hulbert, S. H. 2014. Characterization of a tryptophan 2-monooxygenase gene from Puccinia graminis f. sp. tritici involved in auxin biosynthesis and rust pathogenicity. Molecular Plant-Microbe Interactions 27(3): 227-235.

Zhang, Y., Fan, W., Kinkema, M., Li, X., \& Dong, X. 1999. Interaction of NPR1 with basic leucine zipper protein transcription factors that bind sequences required for salicylic acid induction of the PR-1 gene. Proceedings of the National Academy of Sciences 96(11): 6523-6528.

Zhou, G. A., Chang, R. Z., \& Qiu, L. J. 2010. Overexpression of soybean ubiquitin-conjugating enzyme gene GmUBC2 confers enhanced drought and salt tolerance through modulating abiotic stress-responsive gene expression in Arabidopsis. Plant Molecular Biology 72(4-5): 357-367.

Zimmermann, P., Laule, O., Schmitz, J., Hruz, T., Bleuler, S., \& Gruissem, W. 2008. Genevestigator transcriptome metaanalysis and biomarker search using rice and barley gene expression databases. Molecular Plant 1(5): 851-857.

Zouine, M., Fu, Y., Chateigner-Boutin, A. L., Mila, I., Frasse, P., Wang, H., \& Bouzayen, M. 2014. Characterization of the tomato ARF gene family uncovers a multi-levels posttranscriptional regulation including alternative splicing. PloS One 9(1): e84203. 